\title{
The Influence Factors of Agricultural E-commerce Mode Selection Analysis
}

\author{
Chunrong Zhang \\ Changchun guanghua school, Changchun ,China \\ 294244476@qq.com
}

Keywords: design agricultural products; Electricity; Mode choice; Factor analysis

\begin{abstract}
Agricultural e-commerce is in the electronic commerce based on industrial products to developed on a large scale in recent years, however, produce many factors that affect the choice of electronic commerce mode, agricultural enterprises how to evaluate the effect of various factors on the agricultural electricity model choice is this article's research center. At first, this paper through the analysis of the typical agricultural e-commerce model sum up the characteristics and influencing factors of all kinds of agricultural e-commerce mode; And according to the above theory combining with the characteristics of all the above factors and design out the various factors that affect agricultural mode selection and analysis of the relationship between them, to determine the main factors affecting agricultural e-commerce mode selection and purpose of the relationship between them. Enterprise choose e-commerce model is according to the analysis results presented the main reference factors, and puts forward some relevant Suggestions, hope to produce the choice of operation mode of electricity enterprise or organization and innovation to help.
\end{abstract}

\section{Introduction}

Chunrong Zhang is responsible for The project $<$ jilin province agricultural electronic commerce development countermeasure research $>$ which is named Jilin educational, scientific and cultural [2016] 564 is "2016-2020" social science research project of jilin province department of education.In the study of the subject we found that agricultural e-commerce mode selection and closely related to electronic commerce development countermeasure.This article to our country agricultural product electronic commerce the influence factors of mode selection of research, theoretically explore suitable for the current China's economic and social development under the condition of agricultural e-commerce, choose the method or way of agricultural e-commerce mode and to guide the operating enterprises to select innovative e-commerce mode for agricultural products, promote agricultural e-commerce, as well as the purpose of sustainable development of agricultural industry.

\section{Typical Agricultural E-commerce Mode Analysis}

A.the fresh electricity Farmigo mode

Farmigo is the first truly a bulk electricity, it is within the prescribed period of time, would buy monomer amount reaches a certain size give discount sales. Farmigo in communities, each community, generally more than 20 users, the user community by community leader of exclusive website to order order, local farm weekly summary from the same community order and fixed point distribution, then the order by the users themselves to retrieve their agricultural products. If every retail orders to timely response and distribution, logistics and warehousing costs will crowd out electrical business profits, Farmigo mode through food community gathering orders, delivery, once a week to solve the agricultural electricity storage cost and logistics cost control problems. Farmigo pattern made from the same local community of users never leave home can enjoy the local fresh produce. Its commitment to fresh product price is average price $70 \%$ to $80 \%$, the local supermarket within 48 hours and ensure delivery to their appointed places.

Patterns Farmigo essence promote local fresh agricultural products production and consumption idea, most cities in China there is no large-scale normalized operation of the farm, its quantity and 
category also enough, but in order to realize the localization community group-buying model. At the same time, China's vast, residents' diet structure is complex, consumer diversity, exotic native produce widely popular among consumers all over the country, especially the young Internet groups. Farmigo localization operation mode in China may not.

B. the local model, taking the path of platform

Zhejiang lishui local e-commerce use "electronic retailing + integrated e-commerce service providers, the traditional industry" model, under the policy environment support depends on local comprehensive e-commerce service provider drive agriculture and traditional industries with electronic retailing cooperation in areas such as the agricultural product processing industry, and formed the local ecological e-commerce. The local model is the core of local e-commerce service provider. The local electronic commerce service dominated by then the company has set up a platform matt dragon e-commerce distribution, and is responsible for the collection of local high quality agricultural products supplier product and package on its own platform, is engaged in the electric network of retail each business to put their own circle of product package store sales, platform service provider is responsible for the unified logistics distribution. The entire operation process hence the company play the role of the supply chain management. The platform distribution turnover successively from 2011 to 2011, for 1000, 3500, 80 million yuan. Hence the company to help give him grow at the same time supporting with traditional enterprise electricity development, its help farmers and cooperatives smooth docking electric business channels and promote agricultural industries such as electric after the business benefit, thus improve the local ecological e-commerce, formed the local network operation and network consumption pattern of electronic commerce.

On this basis, the local shop association was established in 2010. Its members include government agencies, the traditional agricultural products operating companies, electric business enterprise personnel. These people have their own resources, through the electronic retailing association together, gather the energy for the local mode development. Since its founding more than 30 games organizing training a total of more than 3000 people, and through the technical consulting platform solutions give him problems at any time. Association packaging based on a matt dragon distribution platform, integrate the local agricultural cooperatives and production base as well as some scattered farmers more than 120 suppliers of resources, the electronic retailing in her store into the distribution platform product package, and will be online store receiving orders to distribution platform, the distribution platform is responsible for the unified logistics distribution. Electronic retailing association through the model implements the agricultural resource intensive management, for the quality of products and logistics services to provide a unified security at the same time reduce the operation cost of the business, and also can help farmers in the process of operation, such as cooperative suppliers to develop new products expand new markets.

In the first half of 2013, the local store a total of more than 1473 members of the association, including 1268 version members and 164 suppliers, and a member of the 41 service providers. Of those members involved in finance, logistics, marketing, design, application of information is closely related to the enterprise the whole management process of industry service providers. The business ecosystem provides about 5000 young urban and rural employment. Traditional agricultural basic version is by the farmers, agricultural cooperatives or agricultural enterprise transformation, its mostly in "network platform $+/$ electronic retailing company + peasant household" docking large market sales distribution model. The local upgrade into farmers and association and the company and give him the cooperation pattern, association of thought online service as the center, the intensive development not only increase the electronic retailing interests, and is convenient for docking upstream and downstream industry standard, quality monitoring at the same time. Association was founded two years, the county increased over 1650 online stores on taobao platform, the cumulative total of more than 2000, including 1200 member stores and more than 20 crown level online store. As shown in figure 1, its members taobao shop sales of 150 million yuan in 2012 . 


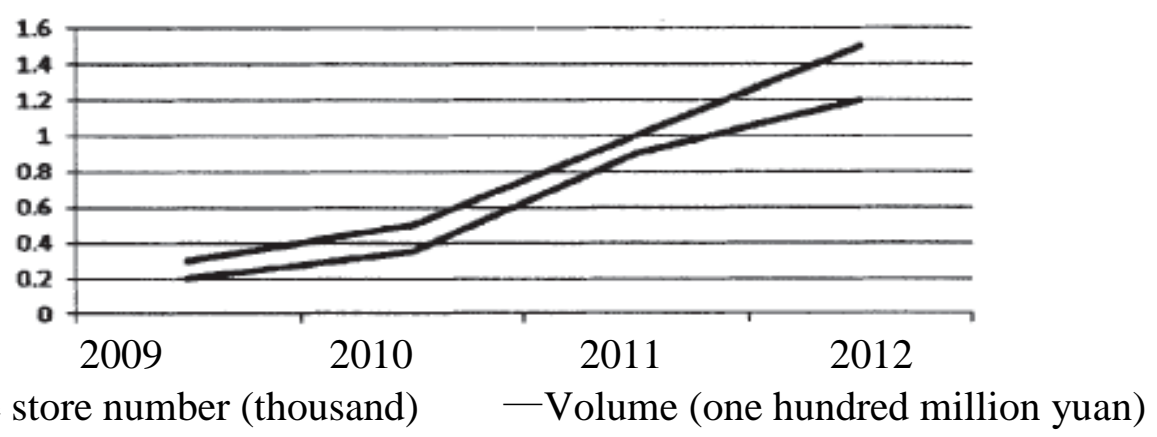

-Online store number (thousand) - Volume (one hundred million yuan)

Fig. 1 The SniChang County shop association online number and turnover tendency chart

The local mode of traditional agriculture as raw materials, give him the basis of the containers, policy as catalyst, comprehensive service as the core of heat. The effect of local mode makes it has started to have been copied tonglu, zhejiang province water town.

C. "Government + service + platform" business model

Characteristics between 2010 and 2013, taobao China project through sichuan, xinjiang, hubei, guizhou, the local five pavilion attempts to explore the "government + service + platform" linkage model. The model have a clear division of responsibilities, service perfect, the key link in service operations, for operating services business management level and market development ability is strong enough, it should not only have the ability to coordinate generation operations and also shoulder the responsibility of the local agricultural e-commerce industry hatching. Guizhou pavilion opened after the special local product sales by the ascent to 400000 daily daily 80-1 million, shows the model has strong ability of special local product sales around the pull.

D."Cycle to buy" mode

The most innovative "cycle to buy" mode, its operation practice from taobao platform. Taobao double 11 electric business activities in 2013, for the fresh type of grain and other agricultural products launched "cycle to buy" mode, shopping users and sellers agreed one-time procurement for half a year or the year of agricultural products, the seller in accordance with the responsible for weeks or months to shopping online distribution of agricultural products. The model can not only save the netizen repeated order of trouble, also reduces the risk of the seller or supplier inventory, at the same time also can reduce logistics cost, is the foundation of implementing order agriculture mode and conditions.

E."Consumption" booking order agriculture pattern

Order agriculture refers to the suppliers and consumers order agreement in advance, for agricultural products by the supplier in accordance with the requirements for the order to arrange production and supply of agricultural products to consumers a kind of agricultural production and marketing mode, with the development of cold-chain logistics and logistics gradually perfect supporting facilities, electric dealer market order agriculture pattern space will be increasing.

Tmall platform based on open to booking a June 2013 patterns and cold-chain distribution system in advance and cherries northwest of the United States signed the sales contract and to booking in advance the Tmall platform cherries order form of trade is a typical agricultural electricity applications. By order agriculture to booking mode can realize time-sharing picking, intensive, in turn, reduce the risk of warehousing and logistics of agricultural products logistics costs, reducing wear and tear, and the savings to the customer, Tmall pre-sales of the cherries take 179 yuan 4 jins pricing schemes and the bag mail, compared with the traditional high price low efficiency offline supermarket at 85 yuan per kilogram of price is much higher, and it is nowadays fresh consumption, consumer experience, a lot. Tmall by bargain, C2B way to gather a lot of orders, greatly improving the quality of the optimization efficiency of the supply chain and distribution services. The growth of the agricultural natural cycle provides a space for C2B operations. Consumers can completely through the $\mathrm{C} 2 \mathrm{~B}$ platform to make an appointment next year the year's rations.

F.OTO multi-platform radiation pattern

OTO multi-platform mode mainly refers to the electricity business enterprise set up more 
business online trade platform auxiliary line product market transactions.To build first-class brand, to prevent internal malicious competition, the company a lot of kung fu, from the marketing management and regional layout on the joining trader with entity stores design and layout and design of the platform of e-commerce sites have a unified standard and requirements, the price of the product, quality, packaging, etc, are the establishment of a unified standard. It is with these standards and requirements, the "west orchard" brand to famous in domestic, the scale of the company to grow. Xinjiang fruit industry co., LTD., relying on the existing online and offline platform, online from single to multiple platforms to promote development, by the mainstream network platform to the general platform development, the promotion offline by first and second line core city to three or four common urban development, from the flow of information online and offline logistics supply chain development gradually to radiation.

G.Cheng county mode, resource integration road

Into the county founded in county government driven by electricity association after built into a small shop in taobao, the main selling local products. "Into" staff member in a local looking for high quality agricultural resources, and in a timely manner will have these resources farmers into the into network platform, ensure the sustainability of the resource supply and the effectiveness of the regulation association. "Net" professional training of a large number of young people to make them through the microblogging, WeChat platform to carry out the micro marketing created $80 \%$ of its sales. Model into a county that "government + association + farmers" model, the characteristics of the model is first and foremost is the government support and offline quality of the integration of agricultural resources. Government head through the network media to publicize local specialty, real-name is credibility, win the trust of customers, won the market, the second is the electronic commerce association in a county mode has played a positive role, through the association of unified platform operation and technical training. Again offline resources integration of the guaranteed quality and supply of agricultural products. Finally with the help of online media marketing strength helped the development of the model, suitable for electric business operations at the start-up stage.

\section{Agricultural e-commerce model component analysis}

A.regional environmental factors (logistics and consumption habits)

For the same product the same operators, at home and abroad, coast and Midwest logistics network in different regional markets, spending habits, consumption concept and consumption to all differences, operators must adjust measures to local conditions to choose suits own e-commerce model. As xinjiang Virginia dani mode is especially suitable for the frontier in remote areas of rural e-commerce development.

B.platform factors (size and specialization degree and the credit)

For the same type product in taobao platform and jingdong audience scale, platform credibility, conversion rate, payment and other factors vary, even within the same wraps the ordinary shop and taobao marketplace Tmall mall flagship store is different, their way of operation, income is very different, like taobao shop is mostly through the low price into large-scale works to obtain profits, while Tmall mall relying more on branding and marketing mode of high input roll money to obtain higher profits. In terms of the platform itself, different platform works, service level difference, the operators can influence the business operation and scientific decision-making, so different platform, model will be more or less differences.

C.product factors (cost and consumer experience)

For dry nuts and fresh products, because they in the transport, storage, and consumption of timeliness requirements, conditions and cost for logistics requirements differ, naturally there is a difference on the operation pattern.

D.scale intensive degree (cost, efficiency and manageability)

Agricultural scale cultivation, intensive operation, not only can improve the operation efficiency, but also can reduce the marginal cost, obtain more spillover benefits. Produce electricity the choice of operation model must consider whether the upstream supply scale and intensive degree in their 
operations.

E.capital and risk factors (technology, strength and trust)

For most agricultural growers are all very want to long distance yourself through the e-commerce of agricultural products export, in order to reduce the risk of pressure goods, and timely collect as many profits as possible, but due to the fact that most farmers in a farmers group limited funding, cannot all have large enterprise all the strength of the mixed operation platform, also does not have the ability to bear the corresponding risks. Behind each model electric business platform is the technology and marketing management, need corresponding capital investment to introduce the corresponding technology and the team to support the operation of electric business platform. So operators can not blindly copying someone else's model, should have enough understanding in e-commerce operation mode, and according to own actual situation to choose suitable for their own e-commerce model. Besides, much the same pattern will be formed between operators compete against each other,, leading to the run state and then cause market operators to rising operating costs and profits decline.

Comprehensive the above analysis it can be seen that agricultural e-commerce model on elements must include logistics, platform, personnel, products four entity elements, on the operation management must include capital, risk, cost, profit, technology, efficiency, scale, brand, trust, such as economic management elements. "Credibility + brand + differentiation" are the three basic essential factors, generally with the help of the government's credibility at or above the county level shall enhance consumer trust, create professional brand make agricultural products to sell higher and farther with local characteristics to find the quality of agricultural products differentiation.

\section{The influencing factors of agricultural e-commerce mode selection analysis}

According to the analysis of agricultural e-commerce model of factors combined with the concept and performance index of the agricultural products e-commerce mode put forward the following hypothesis:

(1)consumer experience affect agricultural e-commerce mode choice: good agricultural e-commerce model consumer experience must not poor, on the contrary good agricultural e-commerce mode, only the consumer experience is the can stand the test of the model, and the experience of consumer and agricultural prices, quality, service, credit, logistics, waiting time, spending habits, etc. These factors have become the potential factors that affect agricultural electricity business mode selection, factors of consumer experience.

(2)Partner satisfaction affect agricultural e-commerce mode choice: good electrical business model, its business partners on the chain should be satisfied, and partnership profits high and low, risk and profit of equivalence, and working capital and play professional competence become the key factors influencing the partners.

(3)the government influence the satisfaction of agricultural e-commerce mode choice: good e-business pattern should be reasonable and lawful management, and tax contribution for the society, so reasonable and lawful management and promote tax become the important factors that affect agricultural e-commerce mode choice.

(4) produce main characteristic is the important factors that affect agricultural e-commerce mode: determining the e-commerce model architecture and process of agricultural products, concrete by agricultural production cycle length, degree of ChanXiaoDe distribution near and far, product characteristic, production scale, the brand level between the influence of high and low, packaging, storage requirements.

(5)the convenience of marketing subject is one of the important factors affecting agricultural e-commerce mode: different e-business models for marketing plan, cost, effect and the efficiency of information transmission requirements are different, and they become the influence factors of electric business mode of agricultural products.

(6)circulation body coordination degree are the important factors that affect agricultural electronic commerce mode: electronic commerce mode of the pros and cons of performance in electricity distribution chain collaboration between economies, embodied spillover effects in 
circulation efficiency, cooperation, collaboration, convenience etc.

(7)Electric business platform main body function is one of the important factors affecting agricultural e-commerce mode: different e-business models have different requirements on the performance of the electric business platform, the platform website content design, techniques, quality standards and the degree of the process specification, the ease of operation, as well as the level of technology and platform the click-through rate and conversion rate of high and low electric business platform is the main performance.

Through the above analysis, we come to the conclusion that agricultural products operating enterprise e-commerce choice of measurable factors are: the main circulation of electric business platform for the ease of operation, ease of collaboration between the main body, marketing costs, the degree of characteristic agricultural products, high and low profit, enterprise credit; Recessive factors are: the main consumer experience, circulation of collaboration, the performance of the electric business platform main body partner satisfaction as well as agricultural products, the main body of the properties of the circulation of one of the most main is main body of the satisfaction degree of collaboration with partners.

\section{Conclusion}

Agricultural e-commerce is in the initial stage of development, and its related businesses and industries with less economic data, study of agricultural e-commerce mostly on time sequence and cannot meet the needs of sample size, makes empirical study and the proportion of the accuracy is lower, due to its initial development stage, the related factors of agricultural e-commerce mode research analysis and consider not purchasing mature, the research method also needs further improvement, at present to produce electronic commerce the influence factors of mode selection of research conclusion to the enterprise practice role in time is limited, with the passage of time and the development of e-commerce of agricultural products, the results will be more and more perfect.

\section{References}

[1] Aliresearch.Taobao village research report2.O[R].Hangzhou:Ali institute, 2013.

[2]Ali institute.Food classification network retail price index.2014.03.15. http://www.aliresearch.com/i_ispi_data/.

[3] Yougao Tian.The definition and scope of agricultural products. Qujing city agricultural network.2009-11-25.http://www.ynagri.gov.cn/qj/newsl066/20091125/223550.shmal.

[4] Lee K O S M Y N.Development and Utilization of the Wholesale Price Information System for Agricultural, Livestock and FisheryProductsinKorea[JournalAracle]

JOURNALOFTHEFACULTYOFAGRICULTUREKYUSHUUNIVERSITY 2010, 55(2): 333-340.

[5]Wen w.A knowledge-based intelligent electronic commerce system for selling agricultural products[Journal Article].COMPuTERS ANDELECTRONICS IN AGRICULTURE.2007, 57(1): 33-46.

Introductions:Chunrong Zhang is responsible for The project $<$ jilin province agricultural electronic commerce development countermeasure research $>$ which is named Jilin educational, scientific and cultural [2016] 564 is "2016-2020" social science research project of jilin province department of education. 